\section{Compliance with Postexposure Prophylaxis for Exposure to Bacillus anthracis Among U.S. Military Personnel - South Korea, May 2015}

Koya C. Allen, $\mathrm{PhD}^{1,2}$; Katherine Hendricks, $\mathrm{MD}^{3}$;

Eric Sergienko, $\mathrm{MD}^{4}$; Raul Mirza, DO ${ }^{5}$; Rohit A. Chitale, $\mathrm{PhD}^{1,6}$

In the United States, Bacillus anthracis is a select agent and is subject to select agent requirements under the U.S. Code of Federal Regulations.* On April 20, 2015, samples of $B$. anthracis spores considered inactivated were shipped from a U.S. Department of Defense (DoD) laboratory at Dugway Proving Ground, Utah, to various laboratories for routine collaborative diagnostics research. On May 22, 2015, CDC was notified of live $B$. anthracis in one sample received by a private company and initiated a response. On May 29, 2015, DoD began reviewing safety practices for generating and handling inactivated $B$. anthracis spores. By June 1, 2015, the Office of the Assistant Secretary of Defense for Nuclear, Chemical, and Biological Defense Programs had established a task force to coordinate the DoD response (1).

The DoD Comprehensive Anthrax Laboratory Review (2) was completed within 30 days and addressed five main objectives: 1) conduct root cause analysis for incomplete inactivation of $B$. anthracis; 2 ) investigate the lack of effective postinactivation sterility testing for detection of live B. anthracis; 3) review DoD laboratory biohazard safety procedures/protocols; 4) determine laboratory adherence to established procedures/ protocols; and 5) identify systemic problems and corresponding solutions. The DoD investigation identified 194 commercial companies, academic institutions, and federal laboratories that had received potentially live $B$. anthracis samples across 50 states, the District of Columbia, three U.S. territories, and nine foreign countries.

In South Korea, the Joint U.S. Forces Korea Portal and Integrated Threat Recognition program works on detection of biologic agents in the environment. A sample of $B$. anthracis was sent to Osan Air Base from the Dugway Proving Ground shipment for research, and $22 \mathrm{DoD}$ personnel were exposed to the sample. Immediately after the event was discovered, these personnel were assessed for the need for emergency postexposure prophylaxis (PEP). On May 27, 2015, all 22 potentially exposed personnel began a PEP regimen tailored to their

\footnotetext{
*http://www.ecfr.gov/cgi-bin/text-idx?SID=f4edcf593150dda1ca3154c98de05 e9e\&mc=true\&node=se42.1.73_13\&rgn=div8.
}

individual vaccination history. Persons lacking prior anthrax vaccination or with expired vaccination history received the standard emergency use protocol for PEP: 3 anthrax vaccine doses over 4 weeks plus 60 days of oral ciprofloxacin $(500 \mathrm{mg}$ twice a day) or doxycycline (100 mg twice a day) $(3,4)$. Persons current for $B$. anthracis vaccination received emergency PEP: 30 days of oral ciprofloxacin or doxycycline $(3,4)$ (Table).

The cohort of exposed personnel was monitored by the Armed Forces Health Surveillance Center, in collaboration with CDC and Army Public Health Center. Cases were monitored for adherence with PEP regimens and onset of symptoms consistent with exposure. No clinical anthrax cases were associated with this incident. Of the 22 persons exposed in South Korea, 14 (63.6\%) who lacked prior anthrax vaccination or had expired vaccination received anthrax vaccine and a 60-day schedule of ciprofloxacin or doxycycline; all 14 completed antibiotics, and 13 of the 14 completed all anthrax vaccine doses. Eight persons who were current for $B$. anthracis vaccination had 30-day antibiotic schedules, with 100\% completing their PEP. No adverse events to vaccination or antibiotics were reported; one pregnant woman was medically advised to transition from ciprofloxacin to amoxicillin.

This unintentional incident that resulted in no clinical cases highlights the importance of vigilance in preparedness and response capabilities for biologic events. Surveillance of potentially exposed military personnel demonstrated near $100 \%$ adherence to required PEP. Although challenging because of the mobility of this unique population, the swift $\mathrm{DoD}$ response ensured control of the population at risk, minimized risk for disease, and demonstrated that a high rate of compliance is achievable in closely monitored otherwise healthy persons.

TABLE. Completion of postexposure prophylaxis (PEP) by U.S. military personnel potentially exposed to anthrax $(\mathrm{N}=22)$, by anthrax vaccination history and military service branch — South Korea, May 2015

\begin{tabular}{lcccr}
\hline & & $\begin{array}{c}\text { PEP among } \\
\text { those current } \\
\text { for anthrax } \\
\text { vaccination } \\
\text { No. }(\%)\end{array}$ & $\begin{array}{c}\text { PEP among } \\
\text { those not } \\
\text { current for } \\
\text { anthrax } \\
\text { vaccination } \\
\text { No. }(\%)\end{array}$ & $\begin{array}{c}\text { Total } \\
\text { completing } \\
\text { PEP } \\
\text { No. }(\%)\end{array}$ \\
\hline Service & Total no. & $3(19)$ & $13(81)$ & $15^{*}(94)$ \\
Navy & 16 & $0(0)$ & $1(100)$ & $1(100)$ \\
Air Force & 1 & $5(100)$ & $0(0)$ & $5(100)$ \\
Total & 5 & $\mathbf{8 ( 1 0 0 )}$ & $\mathbf{1 4}(100)$ & $21^{*}(95)$ \\
\hline
\end{tabular}

* One person completed the antibiotic series but did not complete all anthrax vaccine doses. 


\section{Acknowledgments}

Kevin Russell, Armed Forces Health Surveillance Center; Douglas A. Badzik, Armed Forces Health Surveillance Branch, Public Health Division, Defense Health Agency; Stephen Redd, Office of Public Health Preparedness and Response, CDC. (Note: in 2015, the Armed Forces Health Surveillance Center was officially transitioned to the Armed Forces Health Surveillance Branch, Public Health Division, Defense Health Agency).

${ }^{1}$ Integrated Biosurveillance Section, Armed Forces Health Surveillance Branch, Public Health Division, Defense Health Agency, Falls Church, Virginia; ${ }^{2}$ Counter Biothreats Cell, Force Health Protection, J4 Logistics Directorate, U.S. European Command Headquarters, U.S. Department of Defense; ${ }^{3}$ Division of High-Consequence Pathogens and Pathology, National Center for Emerging and Zoonotic Infectious Diseases, CDC; ${ }^{4}$ Liaison to CDC, U.S. Department of Defense; ${ }^{5}$ Occupational Medicine, Army Public Health Center, U.S. Department of Defense; ${ }^{6}$ Division of Global HIV and Tuberculosis, CDC.

Corresponding author: Koya C. Allen, koya.c.allen.ctr@mail.mil, 49-0711-680-5648.

\section{References}

1. Committee for Comprehensive Review of DoD Laboratory Procedures, Processes, and Protocols Associated with Inactivating Bacillus anthracis Spores. Review Committee report: inadvertent shipment of live Bacillus anthracis spores by DoD. Washington, DC: U.S. Department of Defense; 2015. https://www.defense.gov/Portals/1/features/2015/0615_lab-stats/ Review-Committee-Report-Final.pdf

2. US Department of Defense. Laboratory review. Washington, DC: US Department of Defense; 2015. https://www.defense.gov/News/SpecialReports/DoD-Laboratory-Review

3. Wright JG, Quinn CP, Shadomy S, Messonnier N; Centers for Disease Control and Prevention (CDC). Use of anthrax vaccine in the United States: recommendations of the Advisory Committee on Immunization Practices (ACIP), 2009. MMWR Recomm Rep 2010;59(No. RR-06).

4. US Army Medical Research Institute of Infectious Diseases (USAMRIID). Medical management of biological casualties handbook. 8th ed. Frederick, Maryland: US Army Medical Research Institute of Infectious Diseases; 2014. 